\title{
Ex vivo perfusion techniques: state of the art and potential applications
}

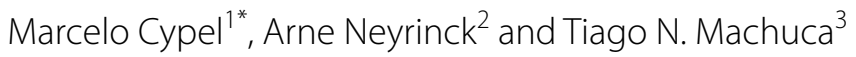

๑ 2019 Springer-Verlag GmbH Germany, part of Springer Nature

\section{Background}

Lung transplantation (LTx) is now a very established treatment for patients with end-stage lung diseases. However, shortage of suitable donors is still a major limitation for realizing the full success of this therapy. Donor lungs from both brain death donors (BDD) and circulatory death donors (DCD) are often injured as a result of brain injury-related cytokine storm, aspiration, infection, fluid overload, ventilator-associated lung injury, and warm ischemia, which prevents them safely being used for transplantation [1]. Attempts to transplant injured donor lungs can lead to high incidence of severe primary graft dysfunction (PGD) and associated short- and long-term consequences to recipients [2]. Therefore, utilization rates of lungs from multi-organ donors is low, ranging from $5 \%$ to $20 \%$.

One of the most attractive strategies to increase donor lung utilization is by improving assessment and treatment of the organ once it is removed from the hostile peri-procurement environment of the donor. In order to achieve this, normothermic ex vivo lung perfusion (EVLP) has been developed over the last 10 years. The first use of EVLP in the more recent era was described by Steen to evaluate function of a DCD with subsequent transplantation [3]. The major contribution by this group was the development of a specific lung perfusion solution (Steen solution, Xvivo perfusion, Sweden) which allows perfusion of the organ without development of pulmonary edema. However, the technique described by Steen was limited in that it only allowed short-term $(60$

\footnotetext{
*Correspondence: marcelo.cypel@uhn.ca

${ }^{1}$ Division of Thoracic Surgery, Department of Surgery, Toronto General Hospital, University of Toronto, 200 Elizabeth Street, 9N969, Toronto, ON M5G 2C4, Canada

Full author information is available at the end of the article
}

min) assessment of the lungs without allowing sufficient time for prolonged organ testing, treatment, and repair. In order to achieve these goals, the Toronto group developed an EVLP methodology that allowed stable lung perfusion and ventilation for $12 \mathrm{~h}$ with maintained physiologic stability $[4,5]$. After extensive additional preclinical studies, this group performed the first clinical trial using EVLP to assess and improve high-risk donor lungs with subsequent transplantation [6]. Since then other clinical studies have been performed using different EVLP methods and different devices for both standard criteria lungs and high-risk donor lungs [7-10]. Currently, most of the lung transplant community believes that EVLP is a very important tool to assess, treat, and recover injured organs, while there is significant skepticism about using this relatively expensive technology for standard criteria organs which normally do well with standard cold static preservation (CSP). Two randomized trials using standard criteria donors with EVLP have demonstrated the safety of the approach but no convincing superiority of EVLP vs. CSP [7, 11]. EVLP indications can be divided in four major categories: (1) high-risk donor lungs from BDD, (2) standard DCDs, (3) high-risk DCDs, (4) logistics (prolongation of preservation time).

1. High-risk donor lungs from BDD: This accounts for the majority of EVLP indications. Donor lungs with borderline oxygenation, pulmonary edema, CXR infiltrates, significant pulmonary emboli, infection, aspiration, or high-risk history (i.e., multiple blood transfusions) can meet this category. EVLP can be used simply to re-evaluate organ quality or to provide active treatments such as antibiotics, thrombolytics, or removal of pulmonary edema by optimal perfusion/ventilation strategies.

2. Standard DCD: These are controlled DCDs (categories 3 , 4, or 5) that present no concerning donor find-

\section{Springer}


Table 1 Most common EVLP methods/systems currently in use

\begin{tabular}{|c|c|c|c|}
\hline & Toronto method & XPS (Xvivo perfusion) & Organ care system (Transmedics) \\
\hline System & $\begin{array}{l}\text { ECMO circuit with reservoir connected } \\
\text { to Xvivo dome and cannulas }\end{array}$ & XPS device & OCS device \\
\hline Perfusate & Steen Solution acellular & Steen Solution acellular & OCS solution blood based \\
\hline Flow & $40 \%$ CO & $40 \%$ CO & $2-2.5 \mathrm{~L} / \mathrm{min}$ \\
\hline Pump & Centrifugal & Centrifugal & Roller \\
\hline Flow pattern & Continuous & Continuous & Continuous \\
\hline Left atrium management & Closed circuit & Closed circuit & Open circuit \\
\hline Left atrium pressure (mmHg) & $3-5$ & $3-5$ & 0 \\
\hline Pulmonary artery pressure & Usually $<12 \mathrm{mmHg}^{\mathrm{a}}$ & Usually $<12 \mathrm{mmHg}^{\mathrm{a}}$ & Target $<20 \mathrm{mmHg}$ \\
\hline Ventilator & ICU type ventilator & Hamilton ventilator built in & OCS ventilator built in \\
\hline Ventilation settings & $\begin{array}{l}7 \mathrm{cc} / \mathrm{min} \text { tidal volume } \\
\text { PEEP } 5 \mathrm{cmH}_{2} \mathrm{O} \\
\text { Rate } 7 \mathrm{breaths} / \mathrm{min} \\
\mathrm{FiO}_{2} 21 \% \\
\mathrm{FiO}_{2} 100 \% \text { (assessment) }\end{array}$ & $\begin{array}{l}7 \mathrm{cc} / \mathrm{min} \text { tidal volume } \\
\mathrm{PEEP} 5 \mathrm{cmH}_{2} \mathrm{O} \\
\text { Rate } 7 \text { breaths/min } \\
\mathrm{FiO}_{2} 21 \% \\
\mathrm{FiO}_{2} 100 \% \text { (assessment) }\end{array}$ & $\begin{array}{l}6 \mathrm{cc} / \mathrm{min} \text { tidal volume } \\
\text { PEEP } 5 \mathrm{cmH}_{2} \mathrm{O} \\
\text { Rate } 10 \text { breaths/min } \\
\mathrm{FiO}_{2} 12 \% \\
\mathrm{FiO}_{2} 100 \% \text { (assessment) }\end{array}$ \\
\hline
\end{tabular}

$\mathrm{FiO}_{2}$ inspired fraction of oxygen

a Pressure is dependent on lung quality since flow and left atrium pressure are fixed

ings prior to or after withdrawal of life-sustaining therapies (WLST). Normally the time from withdrawal to cardiac arrest in this group will be less than $1 \mathrm{~h}$. A significant debate among lung transplant centers exists whether EVLP is required in this category. While some studies have demonstrated that routine use of EVLP provides improved outcomes by ruling out some organs with an unrecognized lung injury that ultimately would lead to significant PGD [12], many centers have demonstrated excellent results with standard DCD donors without the use of EVLP $[13,14]$. Thus, EVLP does not seem to be an absolute requirement for $\mathrm{DCD}$ lung transplantation.

3. High-risk DCDs: These are uncontrolled DCDs or controlled DCDs that have concerning clinical features similar to extended criteria BDDs or donors that take a prolonged time to arrest $(>60 \mathrm{~min})$ after WLST. EVLP can be very helpful in expanding DCD LTx by ensuring stable function of these organs or by repairing warm ischemic injury.

4. Logistics: EVLP can be a powerful tool to extend preservation times from the traditional $6-10 \mathrm{~h}$ to more than $20 \mathrm{~h}$ of total preservation time. Experimental and clinical studies have demonstrated the safety of this approach which has the potential to bring lung transplantation practice to a more semielective fashion with multiple benefits for patients and transplant teams [15].

\section{EVLP assessment}

One key aspect of EVLP is the determination of organ suitability and what parameters one should rely on to deem if the organ is in good quality for transplantation. For most experts on this method, it is clear that evaluation of organ function should be done for several hours (minimum $3 \mathrm{~h}$ ) before the final decision can be made. As lung injury in EVLP is reflected by development of pulmonary edema, lung compliance seems to be the most reliable method to detect early injury. Adjunct parameters such as airway pressures, vascular resistance, gas exchange function, bronchoscopy findings, X-ray images, and direct palpation of the lungs should be evaluated, and stable or improving trends are required for safe lung utilization. Perfusate biomarkers and new technology to measure extravascular lung water are being developed to further refine EVLP assessment for safe transplantation.

\section{EVLP technology and models}

Several industries have now been involved in developing machines for EVLP; however, the two more commonly used commercial devices are the XPS system from Xvivo Perfusion and the Organ Care System (OCS) system from Transmedics. The differences between the most used EVLP methods are described in Table 1. In Toronto, where the single largest experience with EVLP exists, as well as in some European and South American countries, EVLP is performed using off the shelf ECMO-type components and a dome and cannulas from Xvivo and acellular perfusion with Steen Solution. While the model of EVLP provision has been largely used by centers performing EVLP in their own hospitals, more recently an "out of hospital" centralized lung repair center model has been proposed. The Lung Bioengineering (United Therapeutics) center located in Maryland (USA) is actively 
providing EVLP services to several American centers with a marked growth of activities over the last 2 years.

\section{Conclusions}

EVLP has been in clinical practice now for 10 years and it has safely increased lung transplantation activities. While the major benefit of this technology to date has been the ability to test the quality of questionable organs prior to LTx, the major impact should occur in the next few years by implementing more sophisticated organ repair strategies using drugs and biological agents such as gene or cell-based therapies.

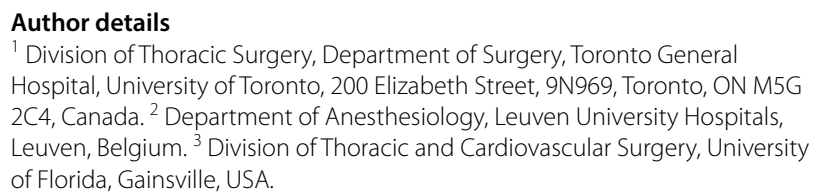
Hospital, University of Toronto, 200 Elizabeth Street, 9N969, Toronto, ON M5G 2C4, Canada. ${ }^{2}$ Department of Anesthesiology, Leuven University Hospitals, Leuven, Belgium. ${ }^{3}$ Division of Thoracic and Cardiovascular Surgery, University of Florida, Gainsville, USA.

\section{Compliance with ethical standards}

\section{Conflicts of interest}

Dr. Cypel is founder and shareholder of Perfusix Canada and XOR labs Toronto. Both of these companies are not in commercial stages. Dr. Cypel is a consultant for Lung Bioengineering and has received research support from Xvivo perfusion and United Therapeutics.

\section{Ethical approval}

An approval by an ethics committee was not applicable.

\section{Publisher's Note}

Springer Nature remains neutral with regard to jurisdictional claims in published maps and institutional affiliations.

Received: 24 November 2018 Accepted: 12 February 2019

Published online: 25 February 2019

\section{References}

1. Munshi L, Keshavjee S, Cypel M (2013) Donor management and lung preservation for lung transplantation. Lancet Respir Med. 1(4):318-328

2. Christie JD, Bellamy S, Ware LB, Lederer D, Hadjiliadis D, Lee J et al (2010) Construct validity of the definition of primary graft dysfunction after lung transplantation. J Heart Lung Transplant 29(11):1231-9
3. Steen S, Sjoberg T, Pierre L, Liao Q, Eriksson L, Algotsson L (2001) Transplantation of lungs from a non-heart-beating donor. Lancet 357(9259):825-829

4. Cypel M, Yeung JC, Hirayama S, Rubacha M, Fischer S, Anraku M et al (2008) Technique for prolonged normothermic ex vivo lung perfusion. J Heart Lung Transplant. 27(12):1319-1325

5. Cypel M, Rubacha M, Yeung J, Hirayama S, Torbicki K, Madonik M et al (2009) Normothermic ex vivo perfusion prevents lung injury compared to extended cold preservation for transplantation. Am J Transplant. 9(10):2262-2269

6. Cypel M, Yeung JC, Liu M, Anraku M, Chen F, KarolakW et al (2011) Normothermic ex vivo lung perfusion in clinical lung transplantation. N Engl J Med. 364(15):1431-1440

7. Slama A, Schillab L, Barta M, Benedek A, Mitterbauer A, Hoetzenecker $K$ et al (2017) Standard donor lung procurement with normothermic ex vivo lung perfusion: a prospective randomized clinical trial. J Heart Lung Transplant. 36(7):744-753

8. Aigner C, Slama A, Hotzenecker K, Scheed A, Urbanek B, Schmid W et al (2012) Clinical ex vivo lung perfusion-pushing the limits. Am J Transplant. 12(7):1839-1847

9. Sage E, Mussot S, Trebbia G, Puyo P, Stern M, Dartevelle P et al (2014) Lung transplantation from initially rejected donors after ex vivo lung reconditioning: the French experience. Eur J Cardiothorac Surg. 46(5):794-799

10. Warnecke G, Moradiellos J, Tudorache I, Kuhn C, Avsar M, Wiegmann B et al (2012) Normothermic perfusion of donor lungs for preservation and assessment with the Organ Care System Lung before bilateral transplantation: a pilot study of 12 patients. Lancet 380(9856):1851-1858

11. Warnecke G, Van Raemdonck D, Smith MA, Massard G, Kukreja J, Rea F et al (2018) Normothermic ex-vivo preservation with the portable Organ Care System Lung device for bilateral lung transplantation (INSPIRE): a randomised, open-label, non-inferiority, phase 3 study. Lancet Respir Med. 6(5):357-367

12. Machuca TN, Mercier O, Collaud S, Tikkanen J, Krueger T, Yeung JC et al (2015) Lung transplantation with donation after circulatory determination of death donors and the impact of ex vivo lung perfusion. Am J Transplant. 15(4):993-1002

13. Levvey BJ, Harkess M, Hopkins P, Chambers D, Merry C, Glanville AR et al (2012) Excellent clinical outcomes from a national donation-after-determination-of-cardiac-death lung transplant collaborative. Am J Transplant. 12(9):2406-2413

14. Cypel M, Levvey B, Van Raemdonck D, Erasmus M, Dark J, Love R et al (2015) International Society for Heart and Lung Transplantation donation after circulatory death registry report. J Heart Lung Transplant. 34(10):1278-1282

15. Yeung JC, Krueger T, Yasufuku K, de Perrot M, Pierre AF, Waddell TK et al (2017) Outcomes after transplantation of lungs preserved for more than $12 \mathrm{~h}$ : a retrospective study. Lancet Respir Med. 5(2):119-124 